\title{
A20 Silencing by Lipid Envelope-Type Nanoparticles Enhances the Efficiency of Lipopolysaccharide-Activated Dendritic Cells
}

\author{
Shota Warashina, " Takashi Nakamura, ${ }^{\text {and Hideyoshi Harashima* }}$ \\ Faculty of Pharmaceutical Sciences, Hokkaido University; Kita 12, Nishi 6, Kita-ku, Sapporo, Hokkaido 060-0812, Japan. \\ Received March 17, 2011; accepted April 18, 2011; published online May 23, 2011
}

In a previous report, we described the development of lipid envelope-type nanoparticles (MEND) modified with octaarginine (R8) and a pH-sensitive fusogenic peptide (GALA) for delivering short interference RNA (siRNA) to mouse dendritic cells (DCs). A20 was recently reported to be a negative regulator of the toll-like receptor and the tumor necrosis factor receptor signaling pathways. Although A20 would be expected to be a useful target for boosting the effects of adjuvants in DC immunotherapy, limited information is available regarding the use of A20-silenced DC by an original non-viral vector. In this study, we loaded anti-A20 siRNA into a MEND and investigated the gene knockdown activity in DC and the immunological functions of A20-silenced DC. The use of a MEND resulted in a significant A20 knockdown effect, and the A20-silenced DC resulted in an enhanced production of proinflammatory molecules, after lipopolysaccharide (LPS) stimulation. The expression of co-stimulatory molecules by LPS stimulation was also increased in the A20-silenced DC. The findings reported herein show that a MEND loaded with anti-A20 siRNA is a potent non-viral vector that has the ability to enhance the adjuvant effect of LPS in DC.

Key words non-viral delivery system; short interference RNA; dendritic cell; A20; multifunctional envelope-type nano device

RNA interference was discovered, ${ }^{1,2)}$ in the latter part of the 20th century. This discovery revealed a promising technique that could be used in functional analyses of endogenous genes, and for curing intractable genetic diseases by the sequence-specific cleavage of mRNA. ${ }^{3-5)}$ Cancer vaccinations represent one of the potentially useful applications for the clinical use of short interference RNA (siRNA). The control of dendritic cell (DC) functions, a powerful antigen presenting cell, by siRNA is especially noteworthy. The suppressor of cytokine signaling 1 (SOCS1) and A20 are useful target genes in DC. SOCS1 is a negative-feedback regulator of the responses of immune cells to cytokines. ${ }^{6)}$ The suppression of SOCS1 gene expression in DCs using a lentiviral vector has been shown to enhance their immunostimulatory capacity and to result in an enhanced antiviral and antitumor response. ${ }^{7,8)}$ In addition, A20 is a zinc-finger ubiquitin-modifying enzyme and inhibits several key proinflammatory signal transduction pathways of the tumor necrosis factor (TNF) receptor, the toll-like receptor (TLR) and the retinoic acid-inducible gene I (RIG-I) in a feedback manner. ${ }^{9,10)}$ In an A20 gene knockdown study using the lentiviral vector, A20 negatively regulated DC maturation and cytokine production, and the A20-silenced DC enhanced antigen-specific T cell responses and antitumor activity ex vivo. ${ }^{11)}$ Therefore, SOCS-1 or A20-silenced DCs appear to have potential for application to DC therapy for cancer. However, viral vectors may have unexpected and serious adverse effects. ${ }^{12)}$ Thus, non-viral delivery systems are essential for successful clinical applications of siRNA.

In a previous study, we reported on the successful silencing of SOCS1 in mouse bone marrow derived DCs (BMDCs). The procedure involved the use of a multifunctional envelope-type nano device (MEND), and the SOCS1silenced BMDCs induced antitumor effects. ${ }^{13)}$ We originally developed the MEND as a non-viral vector, and the MEND is possible to assemble several devices and molecules into a single nano-size structure by controlling their topologies and three-dimensional assignments. ${ }^{14,15)}$ The siRNA-loaded MEND was prepared by mixing an siRNA/stearylated octaarginine (siRNA/STR-R8) complex and small unilamellar vesicles (SUVs). ${ }^{13)}$ The lipid membranes of the siRNA-loaded MEND were modified with R8 and GALA. R8 is a type of cell-penetrating peptide and promotes the cellular uptake of the MEND, and GALA is a $\mathrm{pH}$-sensitive fusogenic peptide that allows endosomal escape. ${ }^{16-19)}$

In this study, we selected A20 as a target of siRNA. A20silenced DC would be expected to have wide applications compared to SOCS1-silenced DC, because the knockdown of A20 results in enhanced adjuvant effects by stimulation with several TLR ligands. ${ }^{20)}$ The A20-silenced BMDC by the lentiviral vector enhanced the production of cytokines after stimulation by a lipopolysaccharide (LPS), a TLR4 ligand, suggesting that TLR4 signaling is promoted by the knockdown of A20. ${ }^{11)}$ TLR4 recognizes components derived from bacteria such as LPS, and signaling via TLR4 promotes the production of cytokines and the activation of immune cells. In contrast with studies using viral-vectors, information regarding the use of A20-silenced DC by a non-viral vector, a particularly original vector, is very limited. ${ }^{21)}$ Therefore, we investigated the knockdown efficiency of A20 by an siRNAloaded MEND in BMDC and the enhancement by LPS stimulation in A20-silenced BMDC.

\section{MATERIALS AND METHODS}

Materials 1,2-Dioleoyl-sn-glycero-3-phosphoethanolamine (DOPE) was purchased from AVANTI Polar Lipids Inc. (Alabaster, AL, U.S.A.). Phosphatidic acid (PA) and LPS were obtained from SIGMA-Aldrich Co. (St. Louis, MO, U.S.A.). Cholesteryl GALA (Chol-GALA) and stearylated R8 (STR-R8) were synthesized by KURABO (Osaka, Japan). The anti-A20 siRNA (5'-CAAAGUUAAUAGUCUAUUATT-3', 5'-UAAUAGACUAUUAACUUUGAA-3') was purchased from QIAGEN (Hilden, Germany). Control 
SiRNA (5'-UACGCGUCAAUCCGUGAUUCCUCUU-3', 5'-AAGAGGAAUCACGGAUUGACGCGUA-3') was purchased from Invitrogen Co. (Carland, CA, U.S.A.). Fluorescein isothiocyanate (FITC) labeled anti-mouse CD80 and CD86 antibody were obtained from Biolegend (San Diego, CA, U.S.A.). The isotype controls of each antibody were purchased from eBioscience (San Diego, CA, U.S.A.). Mouse immunoglobulin $\mathrm{G}(\mathrm{IgG}) 1 \kappa$ was purchased from SIGMAAldrich Co. (St. Louis, MO, U.S.A.).

Animals Female C57BL/6 (H-2 ${ }^{\text {b }}$ ) mice (6 to 8 weeks old) were obtained from Japan SLC, Inc. (Shizuoka, Japan). Mice were maintained under specific pathogen-free conditions. The use of mice was approved by the Pharmaceutical Science Animal Committee of Hokkaido University.

siRNA-Loaded MEND The MEND was prepared by mixing SUVs with a suspension of siRNA/STR-R8. To prepare the SUVs, lipid films containing DOPE and PA at a ratio of $7: 2$ (total lipid content: $0.55 \mu \mathrm{mol}$ ) and $5.5 \mathrm{nmol}$ CholGALA ( $1 \mathrm{~mol} \%$ ) were hydrated with $1 \mathrm{ml}$ of water for $10 \mathrm{~min}$ at room temperature. The hydrated lipid film was then sonicated using a probe-type sonicator, and the siRNA/STR-R8 complex (2.46 nM siRNA) was then mixed with the SUVs at a ratio of $1: 2(\mathrm{v} / \mathrm{v})$. Finally, the surface of the MENDs was modified by adding a STR-R8 solution $(10 \mathrm{~mol} \%$ of total lipid), followed by incubation for $30 \mathrm{~min}$.

Preparation of BMDCs of Mice BMDCs were prepared as reported previously. ${ }^{22)}$ In a typical preparation, bone marrow cells were cultured for $4 \mathrm{~h}$ in RPMI1640 medium containing $50 \mu \mathrm{M}$ 2-mercaptoethanol, $10 \mathrm{~mm}$ 4-(2-hydroxyethyl)1-piperazineethanesulfonic acid (HEPES), $1 \mathrm{~mm}$ sodium pyruvate, $100 \mathrm{U} / \mathrm{ml}$ penicillin-streptomycin, and $10 \%$ fetal calf serum. Non-adherent cells were harvested and cultured in the same medium supplemented with $10 \mathrm{ng} / \mathrm{ml}$ GM-CSF (R\&D Systems, Basel, Switzerland). On days 2 and 4, nonadherent cells were removed, and adherent cells were cultured in fresh medium containing $10 \mathrm{ng} / \mathrm{ml} \mathrm{GM-CSF}$. On day 6 , non-adherent and loosely adherent cells were used as immature BMDCs. The cell surface expression of CD11c in more than $85 \%$ of the cell population was confirmed by flow activated cell sorting (FACS) analysis.

Evaluation of Gene Knockdown Activity of the MEND in BMDCs To evaluate the silencing effect against A20, BMDCs $\left(1.2 \times 10^{6}\right.$ cells $)$ were incubated with the MEND loaded with $20 \mathrm{pmol}$ or $40 \mathrm{pmol}$ siRNA for $2 \mathrm{~h}$ at $37^{\circ} \mathrm{C}$ in $0.5 \mathrm{ml}$ of serum-free OPTI-MEM I containing $10 \mathrm{ng} / \mathrm{ml} \mathrm{GM-}$ CSF in a 12-well plate. Then, $1 \mathrm{ml}$ of RPMI1640 medium containing GM-CSF was added to the cells. After $4 \mathrm{~h}$, LPS was added to the cells at the concentration of $100 \mathrm{ng} / \mathrm{ml}$, followed by a further incubation for $24 \mathrm{~h}$.

After the incubation, BMDCs were collected and isolated using a RNeasy Mini Kit (QIAGEN, Hilden, Germany) according the manufacturer's instructions. To eliminate DNA contamination, the total RNA was treated with DNase I. Five hundred nanograms of total RNA for each sample was reverse transcribed using a PrimeScript reverse transcription (RT) reagent Kit (Takara Bio Inc., Shiga, Japan) with oligodT primer. Quantitative polymerase chain reaction (PCR) was carried out on a 7500 RealTime PCR System (Applied Biosystems, Carsbad, CA, U.S.A.) in $25 \mu$ l aliquots of reaction mixtures containing cDNA, appropriate pairs of primers and SYBR Green Realtime PCR Master Mix (TOYOBO Co.,
Osaka, Japan). A20 level was calculated by the comparative $C_{\mathrm{T}}$ method using glyceraldehyde-3-phosphate dehydrogenase (GAPDH) as endogenous housekeeping genes, respectively. The following primer pairs were used: GAPDH: 5'-AACTTTGGCATTGTGGAAGG-3' (forward); 5'-GTCTTCTGGGTGGCAGTGAT-3' (reverse); A20: 5'-TGCGGAAAGCTGTGAAGATA-3' (forward); 5'-TCTGAACATCTCCAGCGTGT-3' (reverse).

Analysis of Cell Toxicity BMDCs $\left(6 \times 10^{5}\right.$ cells $)$ were incubated with the MEND loading $20 \mathrm{pmol}$ or $40 \mathrm{pmol}$ siRNA for $2 \mathrm{~h}$ at $37^{\circ} \mathrm{C}$ in $0.25 \mathrm{ml}$ of serum-free OPTI-MEM I containing $10 \mathrm{ng} / \mathrm{ml} \mathrm{GM-CSF}$ in 24-well plate. Then, $0.5 \mathrm{ml}$ of RPMI1640 medium containing GM-CSF was added to the cells. After $2 \mathrm{~h}, \mathrm{WST}-1$ was added and the cells were incubated for a further $2.5 \mathrm{~h}$. Cell toxicity was evaluated by measuring the absorbance at $450 \mathrm{~nm}$.

Quantification of Cytokine Production from BMDCs BMDCs $\left(1.2 \times 10^{6}\right.$ cells $)$ were incubated with MEND loading $20 \mathrm{pmol}$ or $40 \mathrm{pmol}$ siRNA for $2 \mathrm{~h}$ at $37^{\circ} \mathrm{C}$ in $0.5 \mathrm{ml}$ of serum-free OPTI-MEM I containing $10 \mathrm{ng} / \mathrm{ml}$ GM-CSF in a 12-well plate. Then, $1 \mathrm{ml}$ of RPMI1640 medium containing GM-CSF was added to the cells. After $4 \mathrm{~h}$, LPS was added to the cells at a concentration of $100 \mathrm{ng} / \mathrm{ml}$, and the cells were incubated for a further $24 \mathrm{~h}$. The concentrations of TNF- $\alpha$ in the culture supernatant were then measured by Quantikine (R\&D Systems, Basel, Switzerland).

Analysis of the Expression of Surface Molecules on BMDCs BMDCs $\left(1.2 \times 10^{6}\right.$ cells $)$ were incubated with the MEND loaded with $40 \mathrm{pmol}$ siRNA for $2 \mathrm{~h}$ at $37^{\circ} \mathrm{C}$ in $0.5 \mathrm{ml}$ of serum-free OPTI-MEM I containing $10 \mathrm{ng} / \mathrm{ml} \mathrm{GM-CSF}$ in a 12-well plate. Then, $1 \mathrm{ml}$ of RPMI1640 medium containing GM-CSF was added to the cells. After $4 \mathrm{~h}$, LPS was added to the cells at a concentration of $1 \mathrm{ng} / \mathrm{ml}$, and the cells were incubated for a further $24 \mathrm{~h}$. The BMDCs $\left(5 \times 10^{5}\right.$ cells $)$ were incubated with $5 \mu \mathrm{g} / \mathrm{ml}$ mouse $\operatorname{IgG} 1 \kappa$ at $4{ }^{\circ} \mathrm{C}$ for $30 \mathrm{~min}$. After washing three times with FACS buffer (PBS containing $0.5 \% \mathrm{BSA}$ and $\left.0.1 \% \mathrm{NaN}_{3}\right), 5 \mu \mathrm{g} / \mathrm{ml}$ antibodies of FITC labeled anti-mouse CD80, CD86 and each isotype control were added to the BMDCs. The BMDCs were then incubated at $4^{\circ} \mathrm{C}$ for $30 \mathrm{~min}$. After washing three times with FACS buffer, the BMDCs were analyzed by FACSCalibur (Beckton Dickinson, Franklin Lakes, NJ, U.S.A.).

Statistical Analysis Pair-wise comparisons between treatments were made using a two-tail Paired $t$-test. Comparisons between multiple treatments were made by one-way analysis of variance, followed by the Scheffe's $F$-test. A $p$ value of $<0.05$ was considered to be a significant difference.

\section{RESULTS AND DISCUSSION}

We prepared an A20 siRNA loaded MEND and a control siRNA loaded MEND. The diameter and zeta-potential of the A20 siRNA loaded MEND were $128 \pm 10 \mathrm{~nm}$ and $31 \pm 2 \mathrm{mV}$, respectively. The diameter and zeta-potential of the control siRNA loaded MEND were also $147 \pm 8 \mathrm{~nm}$ and $31 \pm 4 \mathrm{mV}$, respectively. We first evaluated the A20 gene knockdown activity of the MEND in BMDC (Fig. 1a). BMDCs were treated with the A20 siRNA loaded MEND and the control siRNA loaded MEND, and were stimulated with LPS. Thirty hours after this treatment, mRNA of the BMDCs was determined by a quantitative RT-PCR assay. The MEND showed 
a

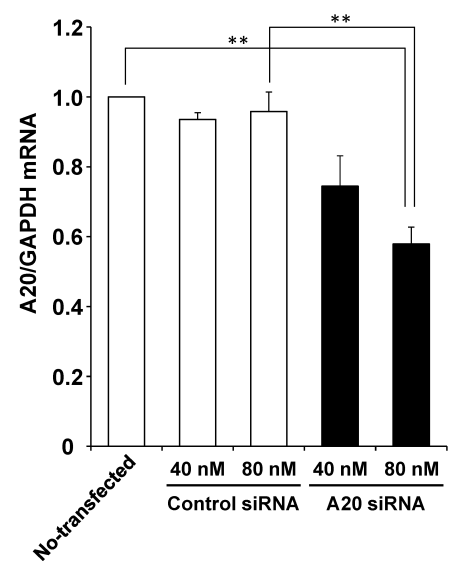

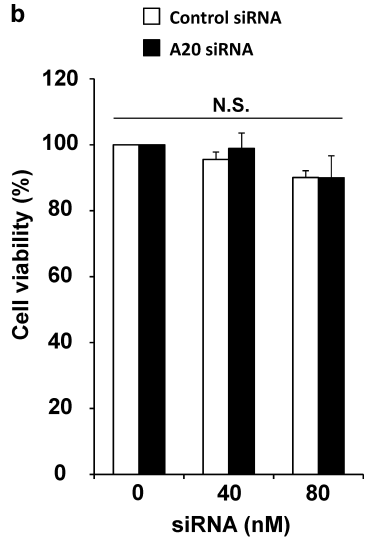

Fig. 1. siRNA Loaded MEND-Mediated A20 Gene Knockdown and Cell Toxicity in BMDC

(a) siRNA-loaded MENDs (40, $80 \mathrm{~nm})$ were transfected into BMDCs $\left(1.2 \times 10^{6}\right.$ cells), and the effects of A20 gene knockdown were evaluated $30 \mathrm{~h}$ after transfection by quantitative RT-PCR. A20 levels were normalized to the values for non-transfected BMDC. Data are the means \pm S.E.M. of three independent experiments. Statistical analyses were performed by one-way analysis of variance, followed by the Scheffe's $F$ test. $* * p<0.01 v s$. no-transfected BMDC and control siRNA. (b) siRNA-loaded MENDs $(40,80 \mathrm{~nm})$ were transfected into BMDCs $\left(6 \times 10^{5}\right.$ cells $)$. After $2 \mathrm{~h}$, WST- 1 was added and the cells were incubated for a further $2.5 \mathrm{~h}$. Cell toxicity was evaluated by measuring the absorbance at $450 \mathrm{~nm}$. The absorbance of $0 \mathrm{~nm}$ siRNA was set to $100 \%$ of cell viability. Zero nanomolar siRNA means no-transfected BMDC. Data are the means \pm S.E.M. of three independent experiments. Statistical analyses were performed by one-way analysis of variance, followed by the Scheffe's $F$-test. N.S.: No significant difference.

an A20 gene knockdown effects at concentrations of $40 \mathrm{nM}$ and $80 \mathrm{~nm}$. At a concentration of $80 \mathrm{~nm}$, the A20 siRNA loaded MEND showed a significant inhibition of A20 mRNA levels compared to the non-transfected BMDC and the control siRNA. The A20 gene knockdown effect at a concentration of $80 \mathrm{~nm}$ was approximately $40 \%$

In general, primary cells such as DCs are weak against transfection, in comparison with other cell lines. It was also necessary to confirm whether the A20 knockdown effect by the MEND was caused by cell toxicity. To address this, we investigated the toxicity of the MEND against BMDC $2 \mathrm{~h}$ after transfection (Fig. 1b). Although the toxicity of the MEND was examined $30 \mathrm{~h}$ after transfection, no cell toxicities were observed (data not shown). During the initial $2 \mathrm{~h}$ period, the BMDCs are incubated with the MEND in serumfree medium. Although cell damages by cationic interactions with the cell membrane are generally decreased when serum is present in the medium, cationic interactions frequently cause cell damage in serum-free media. In addition the possibility that BMDCs could have recovered from the damage $30 \mathrm{~h}$ after transfection cannot be excluded. Therefore, we chose $2 \mathrm{~h}$ after transfection as a reasonable time to evaluate cell toxicity. As a result, no toxicity was detected at concentrations of $40 \mathrm{~nm}$ and $80 \mathrm{~nm}$. It thus appears that the A20 knockdown effect by MEND was not caused by cell toxicity. A concentration of $80 \mathrm{~nm}$ was used in all of the following experiments.

A20 functions as a negative regulator of TLR signaling in BMDC. A20 abrogates TLR4-mediated nuclear factor- $\kappa \mathrm{B}$ $(\mathrm{NF}-\kappa \mathrm{B})$ activation by de-ubiquitinating TNFR-associated factor 6 (TRAF6). ${ }^{23,24)}$ We next examined the production of TNF- $\alpha$ by LPS, a TLR4 ligand and stimulation in A20-silenced BMDC (Fig. 2). BMDCs were treated with the A20

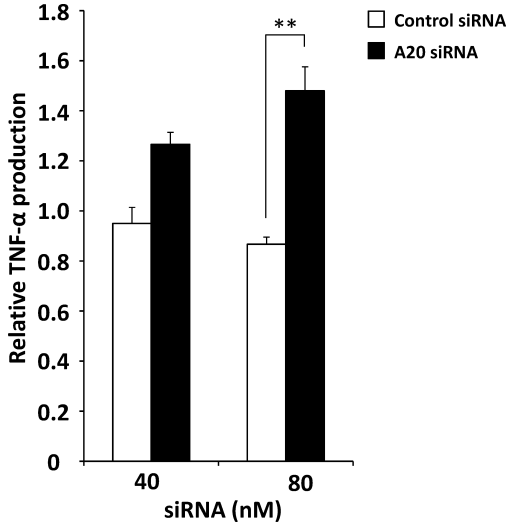

Fig. 2. TNF- $\alpha$ Production in A20-Silenced BMDC

siRNA-loaded MENDs $(40,80 \mathrm{~nm})$ were transfected into BMDCs $\left(1.2 \times 10^{6}\right.$ cells $)$. After $30 \mathrm{~h}$, concentrations of TNF- $\alpha$ in the culture supernatant were measured by ELISA. Concentrations of TNF- $\alpha$ were normalized to the values for non-transfected BMDC. The concentration of non-transfected BMDC was set to 1 . The vertical axis shows relative TNF- $\alpha$ level. Data are mean \pm S.E.M. of three independent experiments. Statistical analyses were performed by the two-tail Paired $t$-test. $* * p<0.01 v s$. control siRNA.

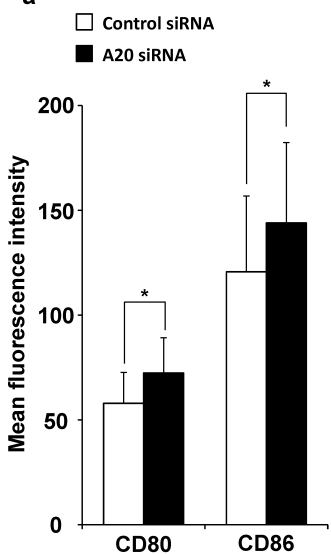

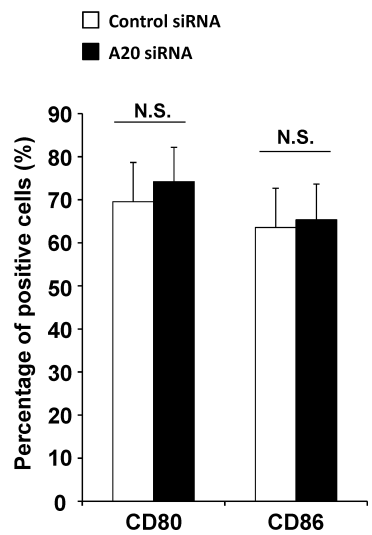

Fig. 3. Expression of CD80 and CD86 in A20-Silenced BMDC

siRNA-loaded MENDs $(80 \mathrm{~nm})$ were transfected into BMDCs $\left(1.2 \times 10^{6}\right.$ cells $)$. After $30 \mathrm{~h}$, the BMDCs $\left(5 \times 10^{5}\right.$ cells) were stained by FITC labeled anti-mouse CD 80 and CD86. (a) The mean fluorescence intensities of the BMDCs were measured by flow cytometry. Data are the means \pm S.E.M. of three independent experiments. Statistical analyses were performed by the two-tail Paired $t$-test. $* p<0.05 v s$. control siRNA. (b) The percentages of positive cells of the BMDCs were measured by flow cytometry. The vertical axis means the percentages of positive cells for conditions in which the percentage of positive cells in the isotype control antibody stained BMDCs was less than $0.5 \%$. Data are the means \pm S.E.M. of three independent experiments. Statistical analyses were performed by the two-tail Paired $t$-test. N.S.: No significant difference.

siRNA loaded MEND and the control siRNA loaded MEND, and were stimulated with LPS. At $30 \mathrm{~h}$ after the MEND treatment, the concentrations of TNF- $\alpha$ in the culture supernatant were measured by enzyme-linked immunosorbent assay (ELISA). The results showed that the knockdown of the A20 gene in BMDC by the MEND resulted in an enhancement in TNF- $\alpha$ production. TNF- $\alpha$ production by A20-silenced $\mathrm{BMDC}$ at a concentration of $80 \mathrm{~nm}$ was significantly higher than that of the control BMDC. TNF- $\alpha$ is produced by NF$\kappa \mathrm{B}$ activation in TLR4 signaling. ${ }^{25}$ ) Therefore, these findings suggest that TLR signaling by LPS stimulation is promoted by the knockdown of the A20 gene by the MEND.

We analyzed the surface expression of various molecules related to antigen presentation by means of flow cytometric assays, because A20 regulates DC maturation. ${ }^{11)}$ Transfected 
BMDCs were stimulated with LPS, stained with an antibody and then analyzed by flow cytometer (Fig. 3). In the case of the analysis of mean fluorescence intensity, A20-silenced BMDC showed significantly higher levels of CD80 and CD86 than the control BMDC (Fig. 3a). On the other hand, in the case of the analysis of the percentage of positive cells, no significant differences between the A20-silenced BMDC and the control BMDC were found (Fig. 3b). These results suggest that the knockdown of A20 mainly promoted the amount of expression of CD80 and CD86 in natural BMDCs. These co-stimulatory molecules, such as CD80 and CD86, enhance interactions with $\mathrm{T}$ cells, antigen presentation and $\mathrm{T}$ cell activation, and result in the promotion of immune responses. These findings suggest that A20-silenced BMDC by a MEND may enhance the effects of dendritic cell therapy.

We succeeded in silencing A20 of BMDCs using an siRNA-loaded MEND. In the A20-silenced BMDCs, cytokine production and maturation were enhanced compared to control BMDCs. The regulation of TLR signaling by A20 is related to the activity of the adjuvant used, and the knockdown of A20 showed a stronger enhancement of immune responses than was observed for SOCS1. ${ }^{11)}$ Therefore, A20silenced DC would be much preferred SOCS1-silenced DC. Finally, these findings show that MENDs have the potential to serve as a potent nonviral vector for A20 gene knockdown in DC immunotherapy.

Acknowledgements This work was supported in part by CREST from the Japan Science and Technology Agency (JST) and Grant-in-Aid for Scientific Research (S) from the Ministry of Education, Culture, Sports, Science and Technology of Japan. We also appreciate Dr. Milton S. Feather for this helpful advice in writing the English manuscript.

\section{REFERENCES}

1) Elbashir S. M., Harborth J., Lendeckel W., Yalcin A., Weber K., Tuschl T., Nature (London), 411, 494-498 (2001).

2) Fire A., Xu S., Montgomery M. K., Kostas S. A., Driver S. E., Mello C. C., Nature (London), 391, 806-811 (1998).
3) Akhtar S., Benter I. F., J. Clin. Invest., 117, 3623-3632 (2007).

4) Grimm D., Kay M. A., J. Clin. Invest., 117, 3633-3641 (2007).

5) Haussecker D., Hum. Gene Ther., 19, 451-462 (2008).

6) Naka T., Narazaki M., Hirata M., Matsumoto T., Minamoto S., Aono A., Nishimoto N., Kajita T., Taga T., Yoshizaki K., Akira S., Kishimoto T., Nature (London), 387, 924-929 (1997).

7) Shen L., Evel-Kabler K., Strube R., Chen S. Y., Nat. Biotechnol., 22, 1546 - 1553 (2004).

8) Song X. T., Evel-Kabler K., Rollins L., Aldrich M., Gao F., Huang X. F., Chen S. Y., PLoS Med., 3, 76-93 (2006).

9) Vereecke L., Beyaert R., van Loo G., Trends Immunol., 30, 383-391 (2009).

10) Hymowitz S. G., Wertz I. E., Nat. Rev. Cancer, 10, 332-341 (2010).

11) Song X. T., Evel-Kabler K., Shen L., Rollins L., Huang X. F., Chen S. Y., Nat. Med., 14, 258-265 (2008).

12) Raper S. E., Chirmule N., Lee F. S., Wivel N. A., Bagg A., Gao G. P., Wilson J. M., Batshaw M. L., Mol. Genet. Metab., 80, 148-158 (2003).

13) Akita H., Kogure K., Moriguchi R., Nakamura Y., Higashi T., Nakamura T., Serada S., Fujimoto M., Naka T., Futaki S., Harashima H., J. Controlled Release, 143, 311-317 (2010).

14) Kogure K., Akita H., Harashima H., J. Controlled Release, 122, 246 251 (2007).

15) Kogure K., Akita H., Yamada Y., Harashima H., Adv. Drug Deliv. Rev., 60, 559-571 (2008).

16) Kogure K., Moriguchi R., Sasaki K., Ueno M., Futaki S., Harashima H., J. Controlled Release, 98, 317-323 (2004).

17) Khalil I. A., Kogure K., Futaki S., Harashima H., J. Biol. Chem., 281, 3544-3551 (2006)

18) Kakudo T., Chaki S., Futaki S., Nakase I., Akaji K., Kawakami T., Maruyama K., Kamiya H., Harashima H., Biochemistry, 43, 56185628 (2004).

19) Li W., Nicol F., Szoka F. C. Jr., Adv. Drug Deliv. Rev., 56, 967-985 (2004).

20) Coornaert B., Carpentier I., Beyaert R., J. Biol. Chem., 284, 82178221 (2009).

21) Breckpot K., Aerts-Toegaert C., Heirman C., Peeters U., Beyaert R., Aerts J. L., Thielemans K., J. Immunol., 182, 860-870 (2009).

22) Nakamura T., Moriguchi R., Kogure K., Shastri N., Harashima H., Mol. Ther., 16, 1507-1514 (2008).

23) Turer E. E., Tavares R. M., Mortier E., Hitotsumatsu O., Advincula R., Lee B., Shifrin N., Malynn B. A., Ma A., J. Exp. Med., 205, 451-464 (2008).

24) Boone D. L., Turer E. E., Lee E. G., Ahmad R. C., Wheeler M. T., Tsui C., Hurley P., Chien M., Chai S., Hitotsumatsu O., McNally E., Pickart C., Ma A., Nat. Immunol., 5, 1052-1060 (2004).

25) Akira S., Uematsu S., Takeuchi O., Cell, 124, 783-801 (2006). 